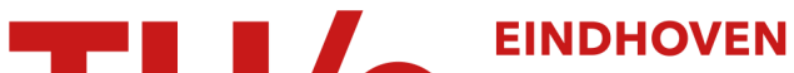 UNIVERSITY OF TECHNOLOGY
}

\section{Isotachophoretic experiments with a counter flow of electrolyte}

\author{
Citation for published version (APA): \\ Everaerts, F. M., Verheggen, T. P. E. M., \& vd Venne, J. L. M. (1976). Isotachophoretic experiments with a \\ counter flow of electrolyte. Journal of Chromatography, 123(1), 139-148. https://doi.org/10.1016/S0021- \\ 9673(00)81110-3
}

DOI:

10.1016/S0021-9673(00)81110-3

Document status and date:

Published: 01/01/1976

\section{Document Version:}

Publisher's PDF, also known as Version of Record (includes final page, issue and volume numbers)

\section{Please check the document version of this publication:}

- A submitted manuscript is the version of the article upon submission and before peer-review. There can be important differences between the submitted version and the official published version of record. People interested in the research are advised to contact the author for the final version of the publication, or visit the $\mathrm{DOI}$ to the publisher's website.

- The final author version and the galley proof are versions of the publication after peer review.

- The final published version features the final layout of the paper including the volume, issue and page numbers.

Link to publication

\section{General rights}

Copyright and moral rights for the publications made accessible in the public portal are retained by the authors and/or other copyright owners and it is a condition of accessing publications that users recognise and abide by the legal requirements associated with these rights.

- Users may download and print one copy of any publication from the public portal for the purpose of private study or research.

- You may not further distribute the material or use it for any profit-making activity or commercial gain

- You may freely distribute the URL identifying the publication in the public portal.

If the publication is distributed under the terms of Article 25fa of the Dutch Copyright Act, indicated by the "Taverne" license above, please follow below link for the End User Agreement:

www.tue.nl/taverne

Take down policy

If you believe that this document breaches copyright please contact us at:

openaccess@tue.nl

providing details and we will investigate your claim. 
ISOTACHOPHORETIC EXPERIMENTS WITH A COUNTER FLOW OF ELECTROLYTE

F. M. EVERAERTS, TH. P. E. M. VERHEGGEN and J. L. M. VAN DE VENNE

Department of Instrumental Analysis, Eindhoven University of Technology, Eindhoven (The Netherlands)

\$

(Received January 7th, 1976)

SUMMARY

A counter flow of electrolyte can be applied succesfully for the separation of large samples at high concentration. The effect of a counter flow of electrolyte on the profile of the zone boundary has been studied. Disturbances are caused mainly by the hydrodynamic flow of the electrolyte, as shown by the application of two different viscosities of the leading electrolyte. The disturbances were recorded with a conductivity detector and a photographic procedure (dyes were applied in combination of uncoloured spacers).

If the effective mobilities of two components differ only slightly, a $100 \%$ counter flow of electrolyte (which is the hydrodynamic flow that is in equilibrium with the "electrophoretic flow") prevents the formation of sharp zone boundaries. Small counter flows of electrolyte, on the other hand, sharpen the zone boundaries and can therefore be usefully applied.

A new type of membrane pump is described for experiments with a regulated counter flow of electrolyte.

\section{INTRODUCTION}

A counter flow of electrolyte can be understood as a hydrodynamic flow of electrolyte in the opposite direction to the direction of migration of the ionic species to be separated. Experiments with a counter flow of electrolyte are performed mainly in order to increase the effective length of the separation compartment. An additional advantage is the fact that high potentials are not needed. This increase in length for separation may be required for various reasons. For example, the ionic concentration of the sample may be so high that the steady state cannot be reached in the available length between the injection point and the detector, which is fixed, and therefore, in the steady state, the sample zones will occupy almost the whole separation compartment. Another possibility is that the difference in concentration of some of the sample constituents may be such that is it impossible to reach the steady state before all of the zones have passed the detector. In these instances, a complete separation cannot be achieved. Another problem can occur if components with nearly identicai effective 
mobilities are present in the sample. It has been proved experimentally that in this instance the use of a counter flow of electrolyte could not improve the separation under the operating conditions that we chose.

Many previous experiments have been carried out with a counter flow of electrolyte in order to achieve an enrichment of components with nearly identical effective (or absolute) mobilities, but they dealt mainly with the separation of isotopes $^{1-6}$. Few papers have dealt ${ }^{7-10}$ with the separation of samples with too high a concentration of the ionic constituents in comparison with the volume of electrolyte inside the separation chamber, or with the separation of samples in which the concentrations of some of the ionic constituents difierer.

In the literature, different techniques can readily be found that involve the use of a counter flow of electrolyte, adjusted to the experimental conditions, equipment and electrolytes used. It is beyond the scope of this paper to give a survey of these techniques. Although we found experimentally that, if a $100 \%$ counter flow of electrolyte is applied (in this instance the hydrodynamic counter flow of electrolyte is in equilibrium with the "electrophoretic flow"), the sharpness of the zone boundaries is lost, we can state that in a moving-boundary system the enrichment of one component in the separation chamber (or in the electrode reservoir in which the electrolyte flows) often can easily be achieved, provided that the difference between the effective mobility of the leading ion and that of the most mobile ionic species of the sample is sufficiently great. Therefore, an enrichment in an "isotachophoretic zone" can be expected if $m_{\text {eff, leading ion }} \gg m_{\text {eff, sample components }} \gg m_{\text {eff, terminatina ion }}$ (where $m_{\text {efr }}=$ effective mobility). As will be shown photographically, the disturbance of the boundary is minimal in this instance.

\section{APPARATUS}

The apparatus consists of two electrode compartments: an injection block and a separation capillary (fluoroethylene poiymer, FEP; $c a$. $50 \mathrm{~cm}$ long, $0.5 \mathrm{~mm} I . D$., $0.7 \mathrm{~mm}$ O.D.). The electrode compartment, on the side at which the counter flow of electrolyte will be applied, consists of a semipermeable membrane (cellulose polyacetate). Experiments with a counter flow of electrolyte were carried out with a membrane pump, regulated by an electronic circuit and with a precise syringe pump (Sage Model 355, Orion Research, Cambridge, Mass., U.S.A.). In the experiments carried out with the syringe pump, no regulation was used because as dyes were applied, the movement of the zones could be studied easily.

The circuitry for the regulation of the membrane pump is shown in Fig. 1. In order to maintain the electric current through the capillary constant, the voltage $V_{c}$ is increased during the analysis, and this increase is used for regulation. If $V_{c}$ reaches a pre-selected value, a current $I_{0}$ will be generated, and this $I_{0}$ generates gas in the electrolysis chamber of the membrane pump (Fig. 2). The volume of this electrolysis chamber will thus expand, because between the electrolysis chamber and the chamber filled with leading electrolyte a thin, pre-stressed rubber membrane is mounted. The flow of liquid, caused by the expansion of the volume of the electrolysis chamber, counteracts the increase in $V_{c}$. Because $V_{c}$ is of the order of kilovolts, its value is reduced to $B V_{c}$ with aid of two resistors $(100 \mathrm{M} \Omega$ and $56 \mathrm{k} \Omega)$. The circuit shown in Fig. 1 compares $B V_{c}$ with an adjustable value $V_{\text {ref. }}$ If $B\left|V_{c}\right|<V_{\text {ref }}\left(V_{\text {sef }}>0\right)$, 


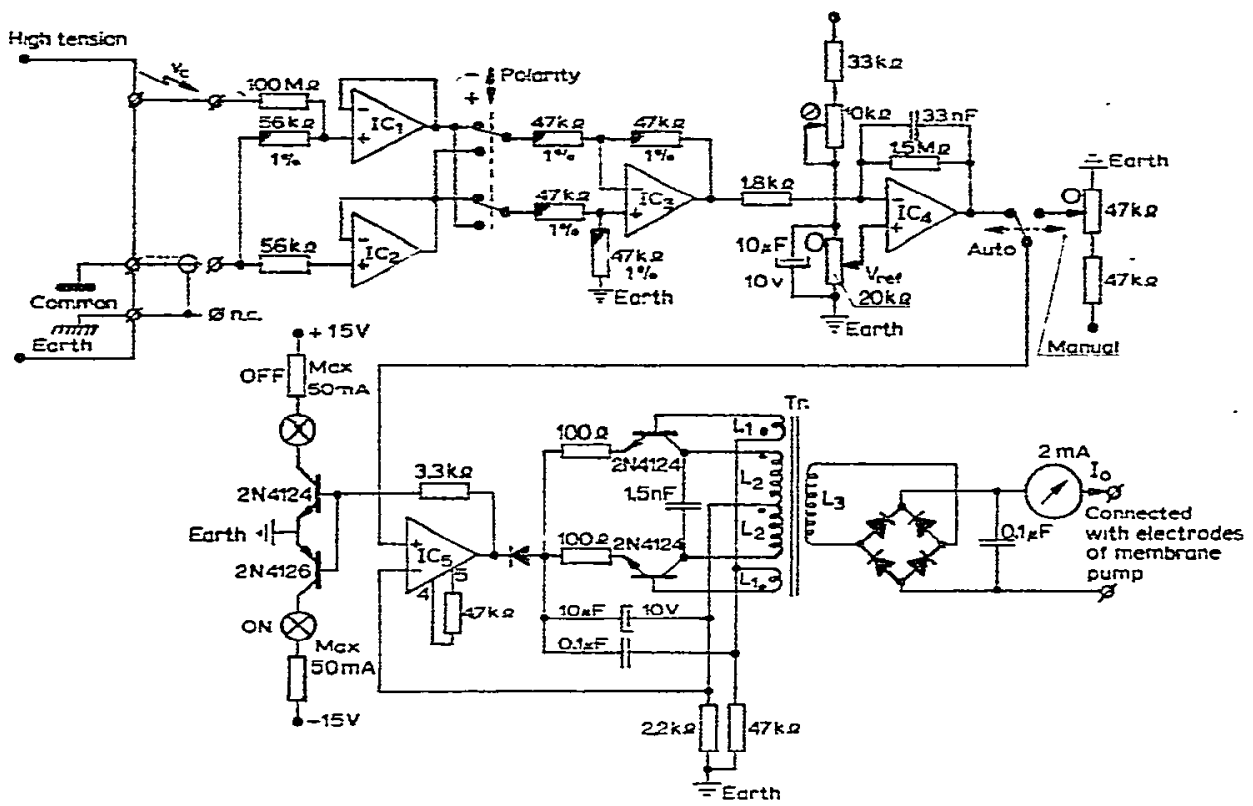

Fig. 1. Electronic circuit for experiments with a regulated counter flow of electrolyte, in combination with the membrane pump shown in Fig. 2. $\mathrm{IC}_{1}-\mathrm{IC}_{5}$ are all $\mu \mathrm{A} 741$. All diodes are $1 \mathrm{~N} 4148$ or $1 \mathrm{~N}$ 914. The transformer $\left(T_{r}\right)$ is made as follows: $L_{1}=2 \times 10$ turns; $L_{2}=2 \times 50$ turns; $L_{3}=65$ turns. The wires used for the transformer are all copper enamelled, $0.4 \mathrm{~mm}$ diameter. For the potcore a P 36/22, 387, $\mu_{\epsilon}=2030$, is used. A modified (current- or voltage-stabilized) Brandenburg (Thoraton Heath, Great Britain) power supply (alpha series) is used.

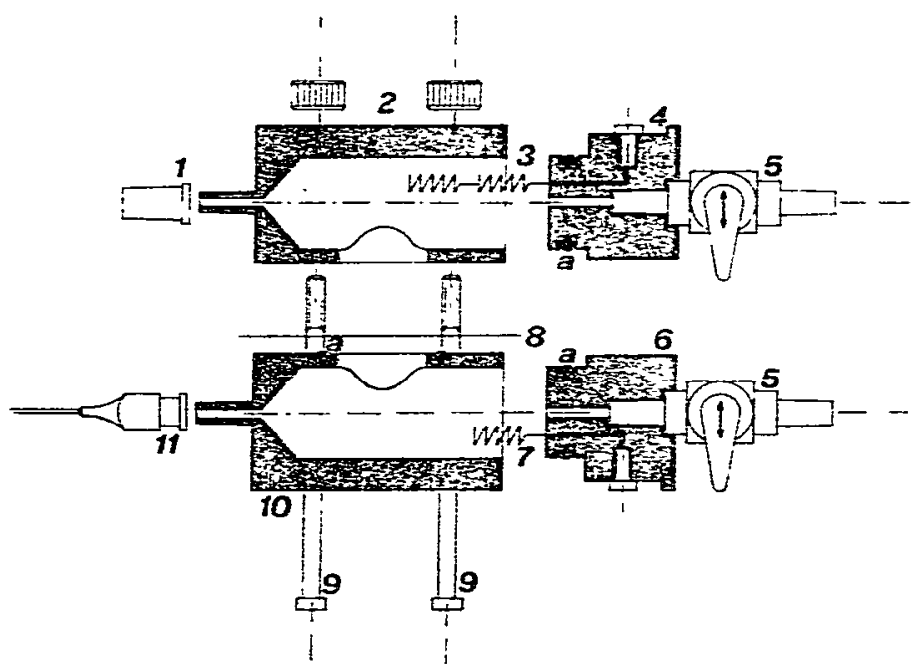

Fig. 2. Membrane pump for use in experiments with a counter flow of electrolyte. $1=$ Cap for closing the electrolysis compartment; 2 = electrolysis compartment; $3=$ electrodes; $4=$ cap for closing the electrolysis compartment; $5=$ Hamilton PTFE-lined valve (1MM1); $6=$ cap for closing the compartment filled with leading electrolyte; 7 = electrode to be used if experiments are carried out without a semipermeable membrane; $8=$ rubber membrane; $9=$ screws and bolts for mounting pices 2 and 10 together; $10=$ compartment filled with leading electrolyte; $11=$ metal syringe. $a=$ Rubber O-rings. 
then $I_{0}=0$. If $B\left|V_{\mathrm{c}}\right|>V_{\mathrm{rer}}$, then $I_{0} \neq 0$ and the increase in $V_{c}$ will thus be counteracted. The reguiation is such that $I_{0}$ will reach a value such that $B\left|V_{c}\right|$ becomes and remains approximately equal to $V_{\text {ref. }}$. In this instance, $I_{0}=A\left(B\left|V_{c}\right|-V_{\text {red }}\right)$.

The optimal value for the amplification factor, $B A=\mathrm{d} Y_{0} / \mathrm{d}\left|V_{c}\right|$, is dependent on, amongst other factors, the electrolytic system inside the capillary tube and its cross-section. If the value of BA is too great, unstable regulation would result, whereas if the value of BA is too small, the accuracy of the regulation would not be sufficient. It needs no further explanation that both the current through the $100-\mathrm{M} \Omega$ and $56 \mathrm{k} \Omega$ resistors and the input current needed for the electronic regulation must be negligibly small compared with the electrophoretic driving current.

A galvanic separation of the electrodes of the electrolysis compartment of the membrane pump and the "earth" (i.e., the electrode of the current-stabilized power supply at low voltage) is needed, because otherwise part of the electrophoretic current will flow through the rubber membrane. It was found experimentally that the rubber membrane used (a contraceptive) eventually became permeable to small ions if a bad galvanic separation was used. Besides the electrical leak, the small ions from the electrolysis compartment of the membrane pump may interfere in the analysis.

The operational amplifiers of the circuit (Fig.1) form a differential amplifier with a high input impedance. The amplification factor of this differential amplifier is unity.

With aid of a switch "Polarity", the output signal of the differential amplifier is always kept positive, depending on the polarity of $V_{c}$. With aid of a 10-turn potentiometer, the reference voltage, $V_{\text {ref, }}$, can be adjusted. The trim potentiometer of 10 $\mathrm{k} \Omega$ must have a value such that the output voltage of the $\mathrm{IC}_{4}$ is zero if $\left|V_{c}\right|=10$ $\mathrm{kV}$ and $V_{\text {ser }}$ has its maximum value. If the absolute value of $V_{c}$ is greater than the selected value of $V_{\text {ref }}$, a negative output voltage of the $\mathrm{IC}_{4}$ results. The amplification factor of the $\mathrm{IC}_{4}$ is constant to within $3 \mathrm{~dB}$ up to approximately $3 \mathrm{~Hz}$. This frequency is sufficiently high to make stable regulation possible. By the low-pass characteristic of the amplifier, the eventual disturbance of the net $(50 \mathrm{~Hz})$ is sufficiently suppressed. The transformer $T_{r}$ and the two $n p n$ transistors form an oscillator. If the input voltage of the $\mathrm{IC}_{5}$ is negative, the sum of the average collector currents of both transistors is proportional to this voltage. The average value of the rectified current through $L_{3}$ (i.e., the current, $I_{0}$ ) is approximately proportional to the input voltage of the $I_{5}$. If this voltage is positive, $I_{0}$ is zero. By means of a resistor of $4.7 \mathrm{k} \Omega$ between the conrection points 4 and 5 of the $\mathrm{IC}_{5}$, the offset voltage of the $\mathrm{IC}_{5}$ is changed in such a way that $I_{0}$ is zero if the input voltage of the $\mathrm{IC}_{5}$ is zero, with manual regulation. The switch "Auto-manuil" permits either automatic regulation or manual operation to je used. The maximum value of $I_{0}$ is approximately $2 \mathrm{~mA}$. The voltage needed is low $( \pm 3 \mathrm{~V})$. The amplification factor, $B A$, of the circuit shown in Fig. 1 for the experiments discussed in this paper is approximately $0.15 \mathrm{~mA} \cdot \mathrm{V}^{-1}$. As already discussed, this factor depends on the cross-section of the capillary, its length and the operational system applied (Table I). From this, we can calculate that $\left|V_{c}\right|$ changes by approximately $14 \mathrm{~V}$ if $I_{0}$ changes from 0 to $2 \mathrm{~mA}$.

\section{EXPERIMENTAL AND RESULTS}

The first experiments invoived the separation of a test mixture of anions: The effective mobilities of the sample components were chosen such that a complete 
TABEE I

OPERATIONAL SYSTEM AT pH 6 SUTTABEE FOR ANIONIC SEPARATIONS

The solvent is water and the electric current is stabilized at $70 \mu \mathrm{A}$.

\begin{tabular}{lll} 
& Electrolyte & \\
\cline { 2 - 3 } & Leading & Terminating \\
\hline Anion & Chloride & E.g., MES* \\
Concentration & $0.01 N$ & Ca.0.01 N \\
Cation & Histidine & Tris \\
pH & 6 & Ca.6 \\
Additive & $0.05 \%$ Polyvinyl alcohol & None \\
& (Mowiol) & \\
\hline
\end{tabular}

The MES (morpholinoethanesulphonic acid) is purified by recrystallization (three times) and the crystals are washed with acetone.

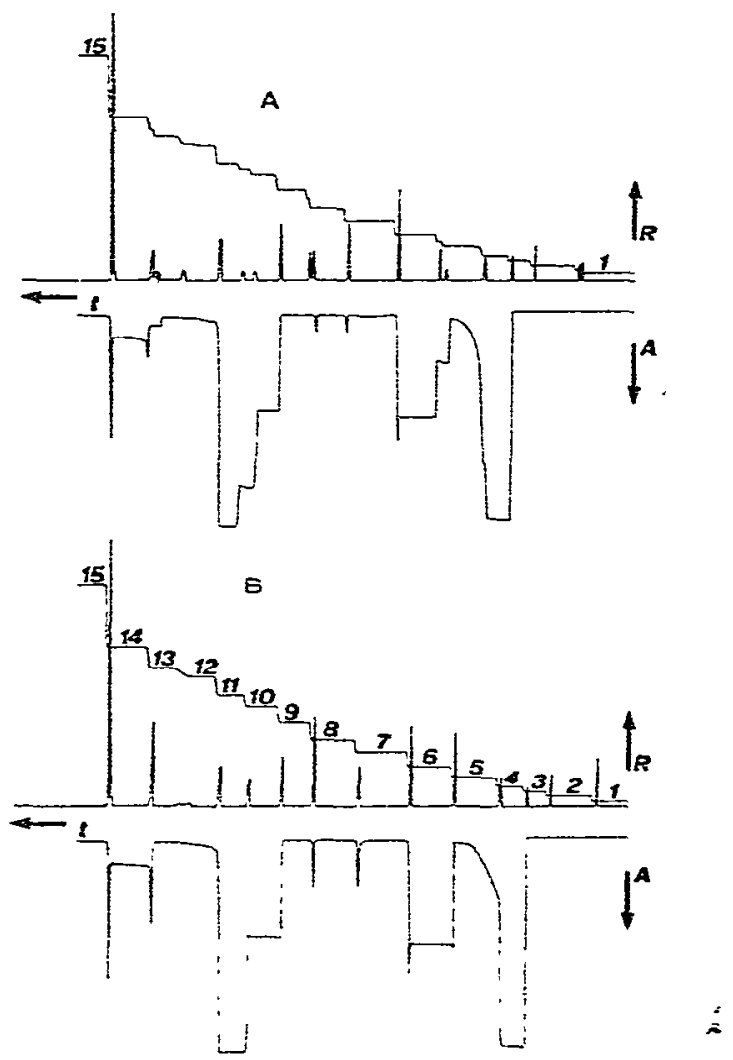

Fig. 3. Isotachopherogram of a standard mixture of anions without (A) and with (B) a counter flow of electrolyte applied by the membrane pump (Fig. 2) in combination with the circuit shown in Fig. 1. In A, many mixed zones are still present. The experiments were carried out in the operational system listed in Table I. 1 = Chloride; $2=$ sulphate; $3=$ chlorate; $4=$ chromate; $5=$ maionate; $6=$ pyrazole-3,5-dicarboxylate; $7=$ adipate; $8=$ acetate; $9=\beta$-chloropropionate; $10=$ benzoate; 11 = naphthalene-2-sulphonate; $12=$ glutanate; $13=$ enanthate; $14=$ benzyl-dl-aspartate; $15=$ morpholinoethanesulphonate. A disturbance due to carbon dioxide from the air can be seen between glutamate and enanthate. $R=$ increasing resistance; $A=$ increasing UV absorbance; $t=$ time. 
separation can be achieved, assuming that the amount of sample injected is not too great for the length of capillary tube available for separation. The operational system applied is listed in Table I. The isotachopherograms in Fig. 3A show the separation of this test mixture when no counter flow of electrolyte was applied, and it can be seen that many mixed zones are still present. A complete separation is shown in Fig. 3B, obtained with a regulated counter flow of electrolyte via the membrane pump for $15 \mathrm{~min}$. The zones must be stopped at least $5 \mathrm{~cm}$ before the detector, in order to prevent any disturbance during detection to the zone boundary profiles. This means that the first sample zone appears about $3 \mathrm{~min}$ after the counter flow of electrolyte has stopped.

In order to make a proper study of the disturbances to the zone profiles during the electrophoretic migration, three dyes were selected with suitable differences in their effective mobilities: amaranth red, bromophenol blue and fluorescein. Acetate and glutamate were applied as spacers for separating these dyes from each other. In the operational system chosen (Table I), $m_{\mathrm{eff}, \mathrm{Cl}}->m_{\mathrm{cff}, \text { amaranth red }}>m_{\text {eff, acetate }}>$ $m_{\text {eff, bromophenol blue }}>m_{\text {eff, glutamate }}>m_{\text {eff. fluorescein }}>m_{\text {eff. morpholinocthane sulphonate }}$ Again, the steady state can easily be reached without any counter flow of electrolyte if the concentrations are chosen properly and not too much sample is injected.

The disturbances to the profiles of the zone boundaries were studied with the aid of photographs. It was found that a $100 \%$ counter flow of electrolyte via the membrane pump (with regulation) and via the Sage syringe pump gave comparable results. The experiments with small counter flows of electrolyte were therefore carried out with the Sage syringe pump, because the counter flow of electrolyte can easily be adjusted manually. The results are given in Fig. 4.

Experiments (a) were carried out in the operational system listed in Table I, while in experiments (b) the viscosity of the electrolytes was increased to approximately $100 \mathrm{cP}$ by the addition of purified hydroxyethylcellulose. In all instances the counter flow of electrolyte was applied after the steady state had been reached, so that the disturbance to the profiles by the counter flow of electrolyte could be compared and the effect shown more convincingly. Both experiments (a) and (b) showed that the influence of the counter flow of electrolyte cannot be neglected, even if careful regulation is applied (see the experiment with a $100 \%$ counter flow of electrolyte, Fig. 4). It was found that with about a $50-60 \%$ counter flow of electrolyte, many zones became mixed.

The shape of the bromophenol blue/glutamate zone boundary was measured precisely from the photographs and the results are shown in Fig. 5. Small counter flows of electrolyte change the parabolic profile into a plug profile. One can use this effect if small amounts of ionic components need to be detected more precisely, because a zone profile can be detected more easily if it has a plug profile. This sharpening effect was also found if conductimetric detection was used applied for recording the zones, as shown in Fig. 6. Here the isotachopherograms of the test mixture of dyes and spacers, separated in the operational system (listed in Table $\mathrm{I}$ ), are shown. These isotachopherograms can be compared with the photographic recording of the test mixture (Fig. 4). A small difference in the optimal sharpness as a function of the rate of counter flow of electrolyte applied can be expected, because the inside diameter of the conductivity probe is different from the inside diameter of the FEP capillary tube.

From the isotachopherograms shown in Fig. 6, one can deduce that small 


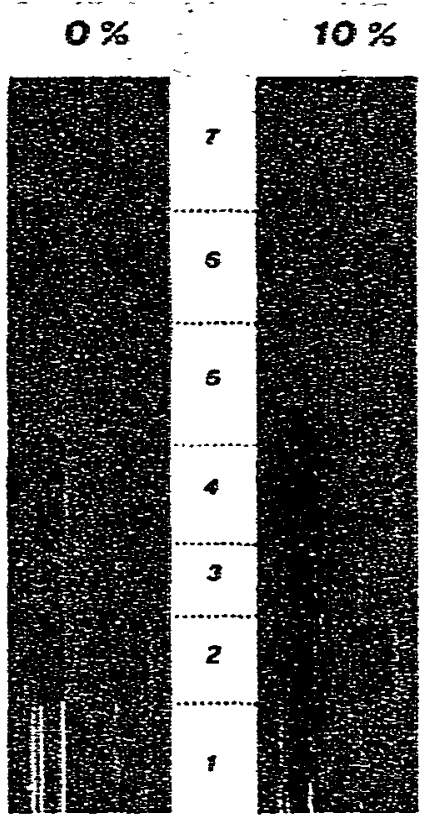

$a b$

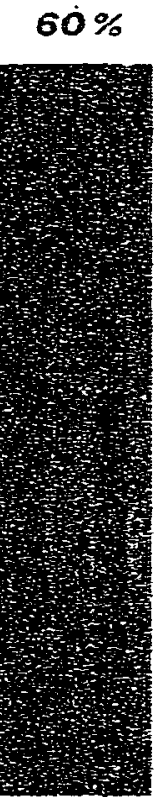

a $b$ a b

$70 \%$

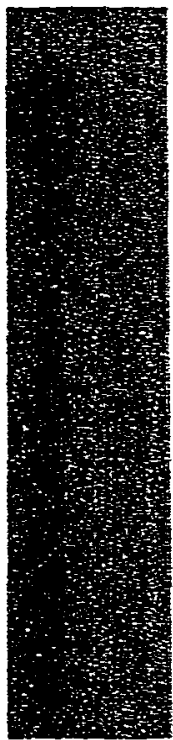

a

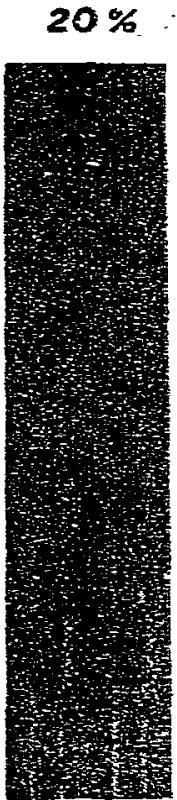

$\mathbf{a} b$

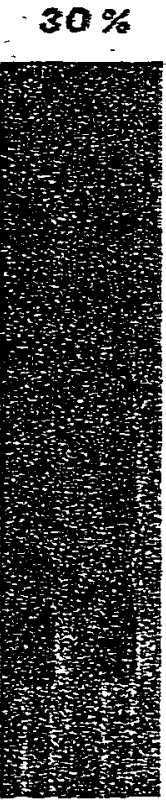

a 6

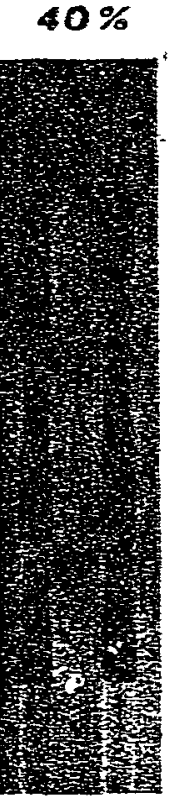

a $b$

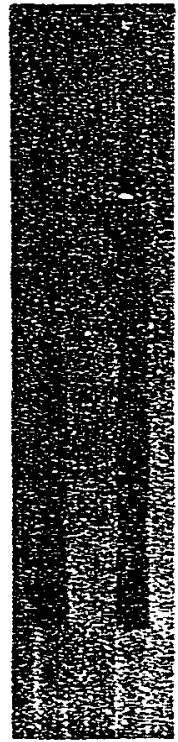

a $b$

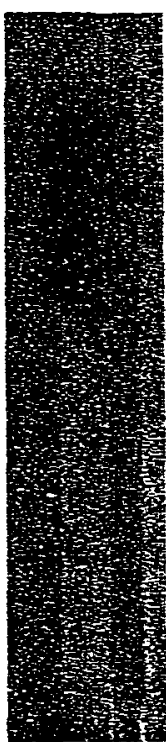

a $b$

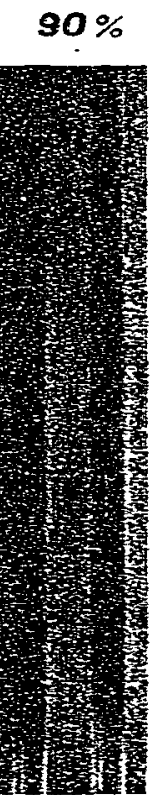

a b

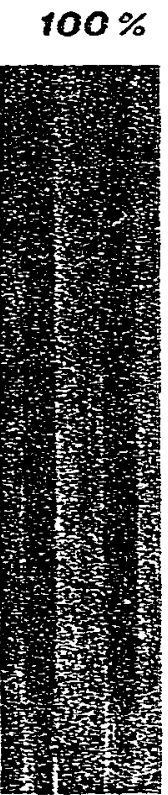

a

b

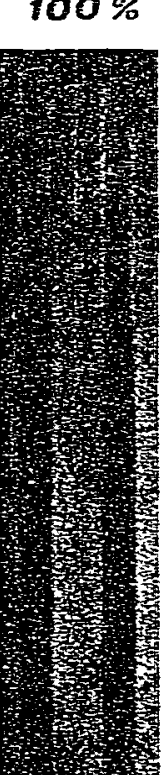

$a b$

Fig. 4. Series of experiments carried out in the operational system at pH 6 (Table 1 ) to show the disturbance to the profiles by a counter flow of electrolyte. In (a) a free solution was applied, while in (b) electrolytes of which the viscosities were increased by addition of hydroxyethylcellulose were used. The viscosity of the electrolytes is about $100 \mathrm{cP}$. From this series of photographs, it can clearly be seen that the zone boundaries are sharpened by a small counter flow of electrolyte and then are disturbed. This disturbance is influenced by the viscosity. $1=$ Chloride; $2=$ amaranth red; $3=$ acetate; $4=$ bromophenol blue; $5=$ glutamate; $6=$ fluorescein; $7=$ morpholinoethanesulphonate. In the two bottom right-hand photographs $(100 \% *)$, two examples are given of the disturbance to the zone boundaries as a function of the efrective mobilities of the consecutive zones: (a) shows the amaranth red/morpholinoethanesulphonate boundary and (b) the amaranth red/glutamate boundary. 

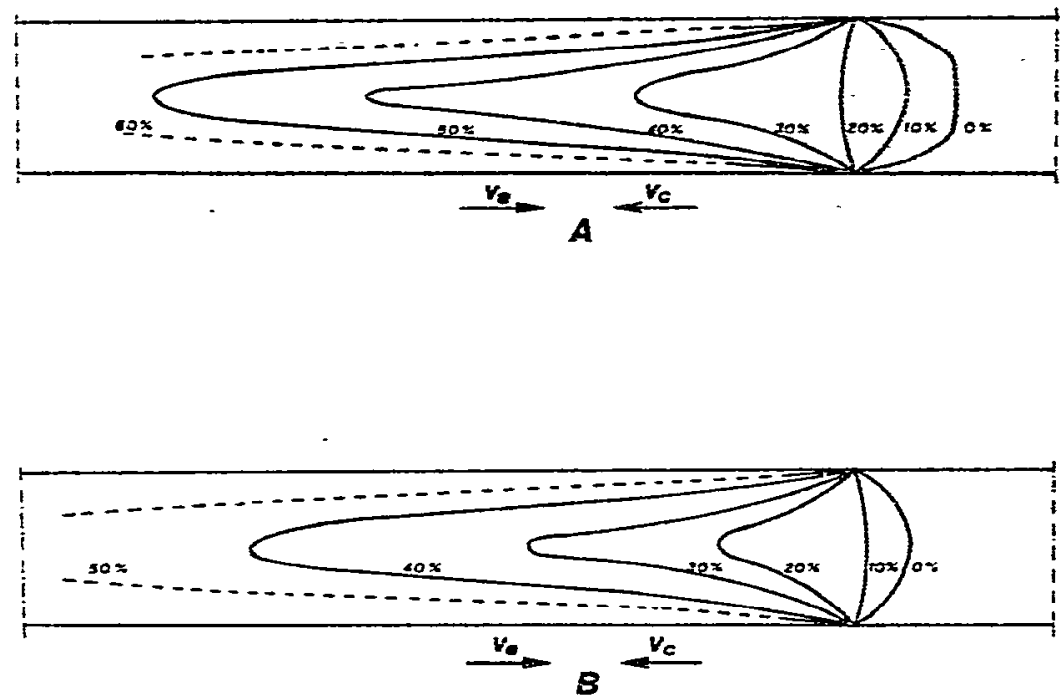

Fig. 5. The disturbance of a profile (bromophenol blue/glutamate) by a counter flow of clectrolyte. Experiments (A) were carried out in a free solution, while experiments (B) were performed at $100 \mathrm{cP}$. $V_{e}=$ electrophoretic velocity; $V_{c}=$ hydrodynamic velocity (counter flow of electrolyte).

zones can in fact be detected more precisely if a small counter fiow of electrolyte is permitted. It should be noted that the recording of the zone boundaries is sharper, although the zones pass the detector more slowly. By this means, the distance between the differential signal of the linear conductivity trace (quantitative information) changes, but it needs no further explanation that one must correct for it.

Because the self-sharpening effect of zone boundaries in isotachophoretic analyses is influenced by the effective mobilities of the ionic species present in the isotachophoretic zones, a series of analyses was carried out in order to study this effect when a counter fiow of electrolyte $(100 \%)$ was applied. Because a visible (by eye) disturbance is often more convincing, the disturbance to the amaranth red/terminator zone bcundary by a counter flow of electrolyte was chosen. The effective mobility of the terminator has been varied. The terminating electrolytes were successive solutions of adipic acid, acetic acid, benzoic acid, glutamic acid, benzyl-dl-aspartic acid and morpholinoethanesulphonic acid. The results of two of these experiments are shown in Fig. $4(100 \%)$. The disturbance by the counter flow of electrolyte was measured more precisely and graphically, as shown in Fig. 5, where the disturbance, as measured photographically is plotted.

From Fig. 5, we can deduce that a complete isotachophoretic separation with sharp zone boundaries can hardly be expected if the difference in the effective mobilities of two ionic species is small in those experiments in which a counter flow of electrolyte is applied. However, an enrichment can be expected if these ionic species are sandwiohed between zones that contain ionic constituents with a high and a low effective mobility; the disturbance to the zone boundaries is small and no sample component will be fiushed away (see Fig. 4, 100\%*).

Because dyes were used to study the infuence of a counter flow of electrolyte on the sharpness of the zone bounc'aries, it was noticed that the zones still migrated, 


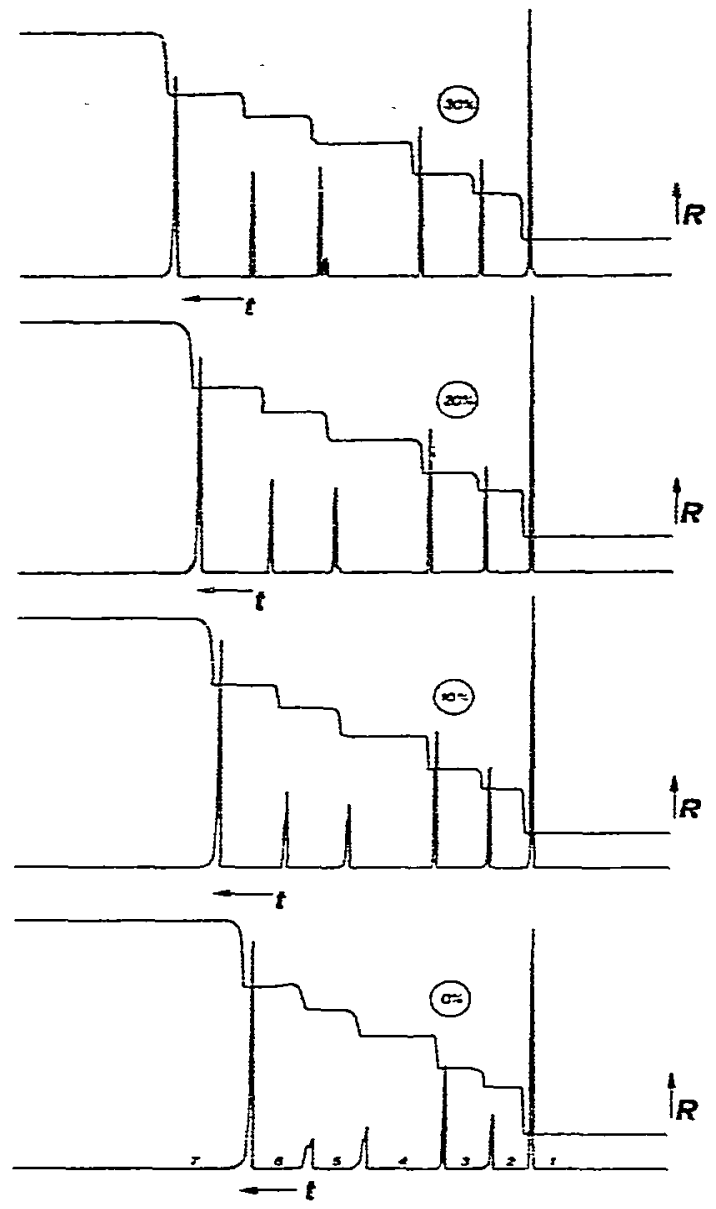

Fig 6. Isotachophoretic separation of the mixture of components shown in Fig. 4, recorded with a conductivity detector. The percentages refer to the percentage counter flow of electrolyte applied. These experiments can be compared with the photographs shown in Fig. $4 . R=$ increasing resistance; : = time.

although a $100 \%$ counter flow of electrolyte was applied and $V_{c}$ was applied for counter flow regulation. An explanation for this effect is as follows. Impurities with an effective mobility between the effective mobilities of the leading ion and the terminating ion will migrate to particular positions in the sequence of zones of the sample according to the effective mobilities of the ionic species and the impurity. An impurity, present in the terminating electrolyte, with an effective mobility higher than that of the terminating ion will decrease the resistance of the zones through which this ionic species passes. A similar, but opposite, behaviour will be shown by those ionic constituents, present in the leading electrolyte, with, effective mobilities smaller than that of the leading ion. These impurities will change the total resistance (and hence $V_{c}$ ) considerably if a $100 \%$ counter flow of electrolyte is applied. Of course, the zones can still move if the total resistance or $V_{c}$ is applied in order to adjust the counter flow of electrolyte to the electrophoretic transport of the ionic species. Attention 
Inust always be paid to the infuence of $\mathrm{H}^{+}$and $\mathrm{OH}^{-}$ions that penetrate into the capillary tube due to the presence of the semipermeable membrane, applied in the counter electrode compartment. Owing to the counter flow of electrolyte, these cisturbances may even enter the capillary tube more quickly. Precautions must therefore be taken in the construction of the counter electrode (membrane) compartment.

Another possible explanation for the movement of the zores when a $100 \%$ counter flow of electrolyte with regulation of $V_{c}$ is applied is the following. If the conditions of the termirating electrolyte are not adjusted to the leading electrolyte (an approximate adjustment is usually sufficient), the change in composition of the terminating electrolyte can change the totar resistance. Similar effects can be expected if a sample is injected at too high a concentration and the counter fiow of electrolyte is started before the zones (with mixed zones still present) of the sample are adjusted to the leading electrolyte. More information is given elsewhere ${ }^{11.12}$.

\section{CONCLUSION}

A counter flow of electrolyte can be applied successfully if the differences between the effective mobilities of the ionic species of the sample are sufinciently large for a complete separation under normal conditions to be expected. A high concentration of the ionic species requires a longer capillary for a desired separation but this, requirement can be overcome by the use of a counter flow of electrolyte. If the differences between the effective mobilities of the various ionic species are so small that under normal conditions no complete separation can be achieved, the use of a counter flow of electrolyte does not improve the separation.

Further research is needed in order to clarify all the phenomena that occur when a counter flow of electrolyte is applied.

\section{ACKNOWLEDGEMENT}

The authors thank Ir. M. Geurts for the development of the electronics shown in Fig. 1.

\section{FEFERENCES}

1 A. K. Brewer and S. L. Madorsky and J. W. Westhaver, Science, 104 (1946) 150.

2 J. W. Westhaver, J. Res. Nat. Bur. Stand, 38 (1947) 169.

3 S. L. Madorsky and S. Straus, J. Res. Nat. Bur. Stand., 38 (1947) 185.

4 B. P. Konstantinov and V. B. Fiks, Russ. J. Phys. Chem., 38 (1964) 895.

5 B. P. Konstantinov and V. B. Fiks, Russ. J. Phys. Chem. 38 (1964) 1038.

6 B. P. Konstantinov and E. A. Bakulin, Russ. J. Phys. Chem., 39 (1965) 315.

7 W. Preetz, Talanta, 13 (1966) 1949.

8 W. Preetz and H. L. Pfeifer, Talanta 14 (1967) 143.

9 F. M. Everaerts J. Vacik, Th. P. E. M. Verheggen and J. Zuska, J. Chromatogr., 49 (1970) 262.

10 F. M. Everaerts, J. Vacik, Th. P. E. M. Verheggen and J. Zuska, J. Chromatogr., 60 (1971) 397.

11 J. L. M. van de Venne, Graduation Rep. Univ. Technology, Eindinoven, 1975.

12 F. M. Everaerts, J. L. Beckers and Th. P. E. M. Verheggen, Isotachophoresis-Theory, Instrumentation and Application, Elsevier, Amsterdam, Oxford, New York. 1976, in press. 